\title{
ORDENAMENTO E DESENVOLVIMENTO TERRITORIAL NO BRASIL: DESAFIOS À SOCIOBIODIVERSIDADE DO CERRADO
}

\author{
Ana Cristina da Silva \\ Universidade Federal de Goiás (UFG), Instituto de Estudos Socioambientais (IESA), Goiânia, GO, Brasil \\ ana.iesa.ufg@gmail.com
}

\begin{abstract}
RESUMO
Ordenamento e desenvolvimento territorial são conceitos constitutivos de políticas públicas que incidem diretamente no território, transmutando-se em políticas territoriais. Tais políticas impactam o território nacional, as regiões brasileiras e o mundo do cerrado, na medida em que afetam a sociobiodiversidade. Nesse sentido, nos detivemos na política nacional de ordenamento territorial (PNOT) que se esboçou no Brasil, na primeira década do século $X X I$, com vistas a identificar seus impactos no cerrado. Nessa perspectiva, consideramos o cerrado como um território, onde coexistem a territorialidade animal e a territorialidade humana, para além das abordagens que o concebem apenas como um bioma. A sociobiodiversidade é a expressão dessa coexistência e de sua complexidade, que desafia as políticas de ordenamento territorial.
\end{abstract}

Palavras-chave: Ordenamento. Desenvolvimento. Território. Cerrado. Sociobiodiversidade.

\section{SPATIAL PLANNING AND DEVELOPMENT IN BRAZIL: CHALLENGES TO THE SOCIO-BIODIVERSITY OF THE CERRADO}

\begin{abstract}
Spatial planning and development are constitutive concepts of Policies that directly affect the territory, transmuting into territorial policies. Such policies impact the national territory, the Brazilian regions, and the Cerrado world, as they affect socio-biodiversity. In this sense, we have stopped at politics national territorial planning system (PNOT) that was outlined in Brazil in the first decade 21st century, with a view to identifying its impacts on the Cerrado. From this perspective, we consider the Cerrado as a territory, where animal territoriality and human territoriality, in addition to the approaches that conceive it only as a Biome. Sociobiodiversity is the expression of this coexistence and its complexity, which Challenges territorial planning policies.
\end{abstract}

Keywords: Planning. Development. Territory. Cerrado. Socio-biodiversity.

\section{INTRODUÇÃO}

O tema do ordenamento e desenvolvimento territorial, no Brasil, não é recente e nem originário da ciência geográfica, encontrando-se presente na economia, na arquitetura, na sociologia e na ciência política. Vinculado à sociobiodiversidade e ao cerrado se descortina uma problemática que põe em questão: conceitos, modelos de ordenamento e desenvolvimento territorial, noções de desenvolvimento e as concepções próprias de sociobiodiversidade e de cerrado.

A noção de sociobiodiversidade implica em ultrapassar as visões economicistas de ordenamento e desenvolvimento territorial e a noção de Cerrado convoca a superar a abordagem meramente ambientalista, que o restringe ao conceito de Bioma, ao mesmo tempo em que o separa da noção de território. A abordagem territorial do cerrado e da sociobiodiversidade demandam uma perspectiva multidimensional e relacional. Ultrapassar esses esquemas intelectuais de pensamento, que toma esses termos de forma isolada e autônoma, constitui um dos desafios dessa temática. 
Identificar os desafios que a temática põe em questão, no plano teórico e metodológico, constitui um dos objetivos de nossa investigação, desenvolvida no âmbito do projeto: "Desenvolvimento territorial e sociobiodiversidade: perspectivas para o mundo do cerrado 1 ". Referenciados no objetivo geral desse projeto, definimos alguns objetivos específicos: compreender a situação do conhecimento científico acerca dos temas centrais e correlatos ao ordenamento territorial e à sociobiodiversidade no Cerrado, com ênfase nas políticas públicas e territoriais; identificar e examinar o papel da legislação e das políticas públicas voltadas ao desenvolvimento territorial atrelado à conservação da sociobiodiversidade no Cerrado. Diante desses objetivos, optou-se pela pesquisa bibliográfica e documental tendo em vista identificar abordagens territoriais no âmbito de políticas públicas que influíram nas concepções de ordenamento e desenvolvimento territorial, que ainda são atuais.

A relevância acadêmica, política e social, dessa temática podem ser identificadas pela importância que os estudos acerca do ordenamento, do desenvolvimento territorial e do cerrado assumiram no século XX. Embora a ocupação e a formação territorial das áreas de cerrado antecedam, no tempo, em muito o processo de colonização portuguesa, foi a partir de meados do século XX que se definiu uma configuração territorial marcada pelo avanço acelerado das relações capitalistas de produção em terras indígenas e quilombolas e dos "povos cerradeiros", motivada em grande parte pelo avanço do agronegócio.

Foi na travessia do século $X X$ para o $X X I$, de modo mais sistemático na primeira década desse século, que uma Política Nacional de Desenvolvimento Territorial (PNOT) foi esboçada. Embora as condições de possibilidade de sua implementação estivessem presentes no cenário nacional, tal política não se efetivou. Nesse período, novos estudos e abordagens sobre território evidenciam a centralidade desse conceito na ciência geográfica e, por isso, constitui o primeiro dos três tópicos apresentados nesse artigo. No segundo tópico, nosso estudo incide sobre o ordenamento territorial como política pública, ou seja, como se esboçou uma política nacional de ordenamento territorial, na primeira década do século XXI. No terceiro tópico destacam-se os "territórios em disputa" e a proposição de uma abordagem territorial do Cerrado. Por fim, essa proposição implica: no alargamento do conceito de território, na implementação de uma política nacional de ordenamento territorial e regional que possa superar os conflitos territoriais e que considere a preservação da sociobiodiversidade.

\section{A CENTRALIDADE DO TERRITÓRIO NA GEOGRAFIA BRASILEIRA CONTEMPORÂNEA}

Desde a instituição da ciência geográfica no século $\mathrm{XIX}$, até o presente momento, que os geógrafos têm se proposto a elucidar a complexidade das sociedades por meio do território, quer seja em relação à política e à economia, quer seja em relação à cultura e à técnica. Na história da geografia, o território sempre esteve vinculado ao Estado, à cidadania e, no século $\mathrm{XX}$, foi associado ao tema do desenvolvimento e do planejamento. Esse estudo incide sobre o conceito território, no pensamento geográfico contemporâneo brasileiro. Buscou-se, nesse pensamento, identificar traços da tradição e de renovação desse conceito, bem como os novos temas a ele associados.

A década de 1990, no Brasil, é exemplar do que se está afirmar, pois foi prodiga em estudos sobre território, por meio de várias abordagens, como os de Santos $(1994,1996)$ e Haesbaert $(1997,1999)$, identificados nas pesquisas de Silva $(2010,2016)$. Nessa década, destacou-se um importante evento cuja temática apareceu com o título de Território, globalização e fragmentação. Apresentado na conferência de abertura do evento, o texto: O retorno do território se tornou emblemático pelas proposições que apresentou (SANTOS, 1994). O "retorno" do território se impôs pela condição histórica e geográfica, naquele final de século, diante do fenômeno da globalização. A "reabilitação" de um conceito, que se impôs também como categoria de análise, demandou uma revisão da história do pensamento geográfico clássico e o esforço intelectual de cientistas sociais e, sobretudo, dos geógrafos evidenciou sua potencialidade teórica, quando se decretava o "fim" dos territórios. O território se mostrou entrelaçado com várias dimensões da vida social, a saber, com: a técnica, a economia e o desenvolvimento; a cultura e a identidade, as migrações, além das tradicionais relações com o Estado, a cidadania e o nacionalismo.

\footnotetext{
1 Nosso estudo se insere nas investigações desenvolvidas no âmbito desse projeto durante o estágio pósdoutoral na Universidade Estadual “Júlio de Mesquita Filho", em Rio Claro, São Paulo.
} 
Os estudos de Silva $(2010,2013,2016)$ demonstram também que as inovações epistemológicas na geografia humana foram promovidas no bojo do Movimento de Renovação da Geografia, na década de 1970, no Brasil. Tal movimento pautou o debate em torno de duas categorias fundamentais do pensamento geográfico contemporâneo: espaço e território. Nos últimos quarenta anos, a geografia humana passou por muitas transformações: seu objeto de estudo foi revisado, seus referenciais teóricos e metodológicos revistos, foram incorporados novos temas de estudos e pesquisas, bem como novas teorias sociais, como analisou Gregory (1996).

Ao examinar a situação da Geografia, no Brasil, Carlos (1992, p. 140) constatou que "as pesquisas na área de geografia humana apontam para a existência de uma multiplicidade de enfoques e abordagens teórico-metodológicas que asseguram a riqueza do processo de construção do pensamento geográfico enquanto exercício de liberdade de pensar-atuar no mundo de hoje". $\mathrm{Na}$ primeira década do século XXI, esse Movimento foi reavaliado em seus desdobramentos e avanços e constatou-se a relevância e o aumento significativo da produção geográfica brasileira com ênfase no território. Essa produção foi fortemente balizada pelos trabalhos de Santos $(1994,1996,2001)$ para o qual, a conjuntura nacional, demandava a elucidação do território e a formulação de uma "teoria geográfica" do Brasil, nessa perspectiva destaca-se a tese de Arroyo (2001). Cabia, pois, à geografia e aos geógrafos compreender a sociedade brasileira por meio de seu território, do "território usado", como se destacou em O Brasil: território e sociedade no início do século XXI. Nesse livro, Santos e Silveira (2001) apresentam uma proposição teórica e metodológica para se estudar a sociedade brasileira por meio de seu território e uma periodização que considera o processo de constituição do meio natural ao meio técnico e deste ao meio técnico-científico informacional.

[...], a teoria maior com frequência se revela insuficiente ao ser mecanicamente adaptada aos níveis menores do real, isto é, às situações nacionais ou infranacionais. Surge, então, o problema das teorias menores. No caso vertente, torna-se necessário elaborar uma teoria menor do país e uma teoria menor do lugar, a serem situadas no plano empírico-teórico. Esse esforço não foi o único propósito dessa obra, mas o de sugerir uma "teoria das mediações", na qual a escolha dos fatos e relações relevantes possa estar apoiada. (SANTOS; SILVEIRA, 2001, p. 12)

Tal proposição expressava também um compromisso de intervenção política na sociedade brasileira, ao mesmo tempo em que definia a importância da Geografia no âmbito das demais ciências sociais. O fenômeno da globalização desafiava as ciências humanas, quanto aos seus referenciais teóricos e metodológicos e seus paradigmas. Nas décadas finais do século passado, quando se decretava o "fim" da história, das utopias e do socialismo, dos estados-nacionais e territoriais modernos, paradoxalmente, constatava-se o "retorno" do território nas análises e teorias geográficas (CLAVAL, 1999).

$\mathrm{Na}$ travessia do século $\mathrm{XX}$ para o $\mathrm{XXI}$, geógrafas e geógrafos se dedicaram à tarefa de pensar os "500 anos" do "descobrimento previsões" do Brasil, o significado e as transformações do território. Assim, Moraes $(2000,2002)$ se ocupou com a formação histórica do território, numa abordagem que concebe a geografia humana como uma história territorial. Santos (2002a, 2002b) ressaltou as anomalias do território promovidas pelos diferentes usos e técnicas ao longo da história do Brasil. Nesses estudos, identificam-se também um sentido profundo em repensar, "redescobrir", o Brasil no contexto mundial, como explicou Becker (1999, p. 11. Grifos nossos).

Redescobrir é olhar o mundo a partir do Brasil, de dentro para fora, pois os processos mundiais operam aqui dentro, afetando de forma diferenciada os países, enquanto muitos outros problemas são internos e têm sua possibilidade de solução também aqui dentro. Redescobrir é olhar o passado com uma visão do futuro, rever e repensar nossas potencialidades e nossas limitações, que têm concretude no território. Redescobrir é olhar o papel do Brasil na atual conjuntura. Enfim, é a base para entender e agir visando uma sociedade melhor.

Contrariando as do "fim" dos territórios (BADIE, 1997) e dos nacionalismos, as primeiras décadas do século XXI evidenciaram a variedade dos temas que puseram em questão a relevância do território na sociedade, tais como: a identidade cultural e territorial, a configuração e a coesão territorial, o planejamento, desenvolvimento e ordenamento territorial. Este último tornou-se tema e objeto privilegiado das políticas públicas e das ciências sociais aplicadas, extrapolando o campo disciplinar da geografia. A geografia humana, a geografia cultural renovada, a geografia humanista, a geografia 
política e a geopolítica contemporâneas foram fortemente impactadas por uma ou outra daquelas temáticas.

Nas discussões sobre a necessidade de uma teoria geográfica para o Brasil, as diferentes técnicas e usos do território, as desigualdades regionais, as perspectivas de desenvolvimento implicavam em repensar o planejamento e as políticas públicas de ordenamento territorial. Assim, emergiram estudos e pesquisas acerca do ordenamento territorial, numa visão panorâmica como apresentadas por Almeida e Soares (2009) e, na escala das regiões de Cerrado, Silva (2009). Como política pública, o ordenamento e desenvolvimento territorial se revelaram duplamente desafiadores como tema de investigação e política de Estado. Questiona-se a existência de uma política de Estado responsável pelo ordenamento territorial, quando constava a existência de várias políticas públicas setoriais, aparentemente dispersas e desconectas, mas que impactavam o território nacional. Outro desafio, teórico e metodológico, se devia à abrangência e precisão conceitual de ordenamento territorial, como exemplifica Silva e Borges (2014, p. 1356-1357):

Para Costa (2005), existem dois equívocos comuns relacionados ao conceito de ordenamento territorial: i) a ideia de que o ordenamento equivale ao planejamento strictu senso; ii) sua imediata redução ao zoneamento, em várias modalidades. Moraes (2005) assinala outro equívoco: a confusão entre os conceitos de ordenamento territorial e regulamentação do uso do solo. Esses se diferenciariam por se tratarem de escalas espaciais distintas, relacionadas a diferentes competências legislativas e executivas, sendo o ordenamento territorial, segundo Becker (2005) uma atribuição da União a ser encarada em escala nacional, a partir de objetivos e estratégias nacionais.

Apesar das críticas sobre a imprecisão conceitual acerca do ordenamento territorial, sabe-se que essa noção põe uma questão política relativa à relação entre Estado e território, ou seja, entre o Estado e seu território nacional. Nessa questão está pressuposta a necessidade de regular ou organizar múltiplos usos e formas de ocupação do território e as transformações promovidas pela sociedade civil, por diferentes sujeitos, agentes privados e instituições públicas e privadas; e considera-se que o ordenamento territorial visa o uso sustentável dos recursos naturais, a distribuição demográfica, a adequação ou assentamento de atividades econômicas.

Numa perspectiva mais ampla, entende-se que uma política de ordenamento territorial é necessária e pode ser mais eficaz e eficiente se a implementação e a gestão de políticas públicas direcionar os modos de desenvolvimento regional e local, promover a integração e a coesão territorial, reafirmar a soberania e a governança. Políticas de ordenamento territorial põem em relevo o modo pelo qual se articula Estado e território nacional. Nesse quadro macro de refletir sobre o país apresentou-se a necessidade de intervir no território nacional, entendido como espaço de governança, por meio de políticas públicas sob o comando do Estado.

\section{O ORDENAMENTO TERRITORIAL COMO POLÍTICA PÚBLICA NO BRASIL}

O aumento do interesse pelos estudos e debates sobre ordenamento territorial, na academia, se tornou mais intenso nas décadas finais do século $X X$ e início do século $X X I$, em várias áreas do conhecimento para além da ciência geográfica. Na primeira década desse século, as condições de possibilidade de uma política nacional de ordenamento territorial pareciam propícias como refere Rückert e Albuquerque (2005, p.15): "Provavelmente, desde o Plano de Metas (1956-1961) e o II Plano Nacional de Desenvolvimento (1976-1980) não se tem momento tão propício como no presente para conjugar planejamento econômico e ordenamento territorial". Esse momento, com a formulação da PNOT, explicita a intervenção pública, estatal, no território. Nesse contexto, entender como o Estado reage às transformações econômicas, políticas, sociais, culturais e ideológicas, seu modo de organização, funcionamento e gestão do território passou a ser uma preocupação central. Alves (2014) faz um percurso histórico-analítico do conceito de ordenamento territorial, dos paradigmas que pautaram as discussões sobre esse conceito em relação com o Estado e identifica o momento em que a análise das culturas de territórios assume relevância na compreensão dos padrões de ordenamento territorial. Nesse percurso, identificou autores e obras, nas décadas de 1990 e 2010 , que pautaram as teorias e concepções acerca da temática. 
O interesse por essa temática na academia está diretamente relacionado com as ações de governo e as políticas de Estado na escala nacional ${ }^{2}$. No Brasil verifica-se uma lacuna temporal entre a promulgação da Constituição e a criação do Ministério da Integração Nacional, em 29 de Julho de $1999^{3}$

Na Constituição Brasileira de 1988, no Artigo 21, parágrafo IX, o termo Ordenação do Território está assegurado como uma das competências da União, a saber: "Compete à União elaborar e executar planos nacionais e regionais de ordenação do território e de desenvolvimento econômico e social". Essa competência não se efetivou em termos de implementação dessa política na década de 1990 e esse tema foi retomado como preocupação governamental no início do século $\mathrm{XXI}^{4}$. Coube à Secretaria de Políticas de Desenvolvimento Regional a elaboração, juntamente com a Associação Brasileira das Instituições de Pesquisa Tecnológica (ABIPT) e o Centro de Desenvolvimento Sustentável da Universidade de Brasília (CDS/UnB), do projeto "Elaboração de Subsídios Técnicos e Documento Base para a Definição da Política Nacional de Ordenamento do Território - PNOT”.

Era necessário que a União definisse diretrizes que servissem de referencial para o ordenamento territorial e que aglutinassem instrumentos já existentes em diferentes níveis de governo - federal, estadual e municipal -, e superar a diversidade de planos, programas e projetos desarticulados. A definição de uma Política Nacional de Ordenamento do Território se apresenta como uma questão política que diz respeito à mudança de "natureza do Estado e do território, e da relação do Estado com seu território" (MIN, 2006). Essa questão política comporta um desafio conceitual ao mesmo tempo em que o ordenamento territorial se apresenta como demanda e estratégia do Estado para gerir e conciliar interesses de diferentes agentes (públicos e privados) e da sociedade civil. O ordenamento territorial implica em ordenar e regular os usos do território, em organizar e definir arranjos espaciais por meio do planejamento e da gestão do território. Tal ordenamento incide sobre a vida da população, as condições sociais e naturais, econômicas, políticas e culturais no território nacional.

À gestão territorial cabe articular a política de ordenamento territorial com a política de desenvolvimento regional, o que cria outro desafio: como articular diferentes instrumentos legais com rebatimento territorial? Além da extensão territorial, o Brasil parece não ter tradição no enfrentamento no tema do ordenamento territorial, ou seja, a tradição brasileira se caracterizaria por uma concepção e aplicação de políticas públicas setoriais, como referem Sander \& Maiorki (2012).

Em 2003, o Ministério da Integração Nacional, por meio da Secretaria de Políticas de Desenvolvimento Regional, foi designado pela Lei Federal № 10.683 de 20 de maio de 2003, (Artigo 27 - inciso XIII - letra L e parágrafo $3^{\circ}$ ), a implementar o Programa de Gestão da Política de

\footnotetext{
2 Em vários países, pesquisadores universitários atuaram como consultores e/ou coordenadores de estudos, na elaboração de diagnósticos e documentos de referência para políticas públicas de ordenamento territorial. A título de exemplo, temos o geógrafo João Ferrão, em Portugal, investigador com atuação em redes internacionais de pesquisa, em projetos da Comunidade Europeia, na OCDE, e na presidência da Associação Portuguesa para o Desenvolvimento Regional (APDR). No Brasil, a geógrafa Bertha K. Becker (1930-2013) atuou como professora e pesquisadora na Universidade Federal do Rio de Janeiro (UFRJ), consultora do Itamaraty, do Ministério de Integração Nacional onde coordenou o estudo temático 4: Logística e ordenamento do território.

3 O Ministério da Integração Nacional foi criado, no governo de Fernando Henrique Cardoso (1995-2002), pela Medida Provisória n. 1.911-8, convertida em Lei n. 10683/2003, aprovada pelo Decreto n. 5.847 de 14 de julho de 2006. Uma de suas competências era a Ordenação Territorial. O MIN foi extinto pela Lei $N^{\circ} 13.844$, de 18 de junho de 2019, com a criação do Ministério do Desenvolvimento Regional, no primeiro ano de governo de Jair Messias Bolsonaro.

${ }^{4} \mathrm{Na}$ avaliação da Comissão, composta por Bertha K. Becker (coordenadora), Adma H. de Figueiredo, Cládio Stenner e Mariana H.P. de Miranda, que elaborou um dos Documentos Temáticos de subsídio à PNOT, havia um projeto nacional que entrou em crise com o processo de redemocratização e o advento da globalização: "No projeto nacional-desenvolvimentista conduzido pelo Estado $(1930$ - 1980) cuja atuação culminou com o "milagre" (1968-72) e a Política de Integração Nacional (1970), a lógica do projeto nacional e do planejamento territorial era bem clara: modernização conservadora acelerada da sociedade e do território nacional capaz de elevar o Brasil à condição de potência. [...]. Esgotado o projeto nacional-desenvolvimentista, à crise do Estado correspondeu à crise no planejamento centralizado e no território, com a entrada em cena de novos atores que se fortaleceram na década de noventa com a redemocratização do país. É no contexto da redemocratização que se anuncia a necessidade de alterar o papel do Estado e do planejamento na promoção do desenvolvimento em novas bases, alteração essa que não era de forma alguma clara e nem poderia ser em face do contexto das crescentes demandas sociais e do avanço da globalização". (2006).
} 
Desenvolvimento Regional e Ordenamento Territorial. Foi criada uma comissão de especialistas, das universidades brasileiras, para elaborar uma de Proposta de Política Nacional de Ordenamento Territorial (PNOT). A comissão realizou o diagnóstico e apontou Questões Atuais do Ordenamento do Território no Brasil: acentuada desarticulação e dispersão da ação do Estado na gestão integrada do território; fortes disparidades demográficas entre as regiões litorâneas e interioranas; forte concentração espacial das atividades econômicas ao longo do litoral, nas áreas metropolitanas e nas regiões Sudeste e Sul; dificuldades, para o Estado, na promoção da integração espacial dos fluxos econômicos; conflitos de uso, territórios onde prevalece a lógica de grandes empresas, em detrimento de grupos sociais menos poderosos, oposição e disparidade entre logística das grandes empresas e da produção familiar; predominância absoluta das rodovias no sistema de transporte; disparidades na distribuição territorial das redes de informação de longa distância; insuficiência de uma infraestrutura de logística orientada para a integração continental; baixa exploração da navegação hidroviária no território nacional; distribuição desigual da infraestrutura de armazenagem no território nacional; distribuição desigual da malha ferroviária e é mal explorada; a distribuição e o acesso à energia não são homogêneos no país, concentrando-se no centro-sul; padrão predatório da expansão das fronteiras de produção com forte desmatamento ao longo dos eixos de expansão da fronteira agropecuária; conflitos fundiários pela propriedade e controle do território e superposição de categorias de uso; constituição do mercado de terras pode ser vetor de exclusão de direitos ao território; fortes contrastes socioeconômicos entre as regiões Sul-Sudeste e Norte-Nordeste; hierarquia das cidades e áreas de influência profundamente desiguais (Sander e Maiorki, 2012, p. 233).

O trabalho da comissão resultou num conjunto de documentos para consulta e orientação para subsidiar o Ministério da Integração Nacional ${ }^{5}$. Todo o trabalho desenvolvido pela comissão e as diretrizes desse Ministério apontavam na direção de uma Política Nacional de Ordenamento Territorial, cujo diferencial e complexidade estava na busca e na tentativa de propor soluções e diretrizes a partir de seis temáticas: Tema1, O padrão de uso e ocupação do território e as principais tendências de transformação; Tema 2, Avaliação dos impactos de Planos, Programas e Projetos no Uso e Ocupação do Território no Brasil; Tema 3, Políticas de Ordenação do Território - A contribuição de experiências nacionais e internacionais; Tema 4, Logística e Ordenamento do Território; Tema 5, Espaços geográficos sob poder da União - uma avaliação da experiência na perspectiva de uma PNOT; Tema 6, Avaliação do Aparato Institucional e Jurídico-legal na perspectiva da PNOT. A cooperação entre Estado e academia indicava uma possível articulação entre teoria e prática, como também as dificuldades em compatibilizar política e ciência numa abordagem territorial. Logo no início da PNOT, outra dificuldade se impôs e emergiram dois modelos de intervenção no bojo da abordagem territorial.

Enquanto a PNOT marcava a tentativa de incorporação e implementação de um modelo de planejamento - o Ordenamento Territorial (OT) - pelo Ministério da Integração Nacional (MI); o lançamento do Programa Nacional de Desenvolvimento Sustentável de Territórios Rurais (PRONAT) e o Programa Nacional de Fortalecimento da Agricultura Familiar (PRONAF) marcavam, por seu turno, a incorporação e desenvolvimento de outro modelo de planejamento, também denominado territorial, empreendido pelo Ministério do Desenvolvimento Agrário (MDA) no âmbito do Reordenamento Agrário e do chamado Desenvolvimento Territorial Rural Sustentável (DTRS) do Brasil. Cada qual focado em intervenções específicas e desarticuladas entre si. (ALVES, 2017, p.10)

Alves (2017) avalia que a formulação e implementação da PNOT não avançou com os planos e programas que foram lançados, coexistindo no mesmo período. As sobreposições de competências, os antagonismos e choques de interesse e a desarticulação entre eles foram outras das tantas dificuldades da PNOT. Durante os anos de 2007 e 2008, o governo buscou apoio a favor da PNOT junto ao Senado e à Câmara dos Deputados por meio de um projeto de lei que tramitou lentamente até 2009. Era a sinalização de que se pretendia consolidar uma política de Estado. Esse processo parecia indicar que a tradição de políticas setoriais de desenvolvimento regional ocuparia teria outro nível de importância no interior da $\mathrm{PNOT}^{6}$. No entanto, além da lentidão do projeto de lei, a PNOT

\footnotetext{
${ }^{5}$ Ao Ministério da Integração Nacional competia a Ordenação Territorial, formular e conduzir a política de desenvolvimento nacional integrado, tendo como diretriz a Política Nacional de Desenvolvimento Regional (PNDR) como instrumento de orientação de programas e ações.

${ }^{6} \mathrm{O}$ histórico desse processo parece indicar que o debate sobre políticas territoriais foi centralizado pela criação de uma Política Nacional de Desenvolvimento Regional (PNDR), mediante o Decreto № 6.047, de 22 de
} 
passou a ser coordenada pela Casa Civil, onde desapareceu silenciosamente. No período de 2003 a 2009, uma fase importante do planejamento, no Brasil, avançou e recuou vertiginosamente. Todavia, as discussões teóricas e conceituais, metodológicas e políticas foram significativamente alargadas nessa primeira década do século XXI7.

Houve importantes mudanças paradigmáticas nas concepções de ordenamento territorial, mas permanecem muitas dificuldades de se estabelecer estruturas ou quadros de apoio na "ausência de padrões teóricos, metodológicos [...] para elencar os elementos culturais locais que devam ser levados em consideração na análise e que podem ser julgados como 'similares' à comparação", como refere Alves (2014, p. 71), que e alerta também para a necessidade de "pesquisas comparativas de culturas de ordenamento territorial [que] se apresentam como campo fértil e desafiador aos estudos que abordam as particularidades dos territórios e de seus elementos basilares: cultura, território, sociedade e Estado" (2014, p. 71). Nesse sentido, seu alerta destaca as considerações de Ferrão (2011, p. 25) sobre as dificuldades que o predomínio de uma "cultura política e administrativa pouco favorável à coordenação intersetorial de base territorial e a ausência de uma cultura cívica de ordenamento do território" 8. Embora o geógrafo português se referisse ao seu país, essas dificuldades são sintomáticas e encontradas em vários outros países para além do continente europeu, como no Brasil.

\section{TERRITÓRIOS EM DISPUTA E UMA ABORDAGEM TERRITORIAL DO CERRADO}

$\mathrm{Na}$ literatura corrente parece haver um consenso quanto ao marco temporal, segunda metade do século $X X$, a partir do qual se evidencia o crescimento de estudos sobre o Cerrado. Outro consenso diz respeito ao avanço do modelo de desenvolvimento capitalista, liderado pela expansão do agronegócio, de monoculturas e do extrativismo predatório (que são exemplo as carvoarias), nas regiões de cerrado. Nas décadas de 1950-1960, com a construção de Brasília, o incentivo ao povoamento e o ideário desenvolvimentista marcaram a acentuada inserção do cerrado do centrooeste brasileiro no quadro dos grandes projetos nacionais, nas políticas públicas desse século, como refere Pereira (2009). Tal inserção acentuada teve como consequências graves ameaças ao bioma Cerrado que não teve a mesma salvaguarda constitucional, na condição de patrimônio nacional, com a Amazônia, a Mata Atlântica e o Pantanal.

Inocêncio (2010), numa abordagem geopolítica, ressalta a estratégia geopolítica do capital internacional em sua expansão pelo Cerrado, por do Programa de Cooperação Nipo-Brasileiro para o Desenvolvimento do Cerrado, o PRODECER, na década de 1970. A modernização territorial do Cerrado foi impulsionada pelos investimentos privados, por meio do campo, com produtos alimentícios e insumos básicos.

Na década de 1970, o Cerrado tornou-se uma "fronteira permitida", campo de pesquisas e programas governamentais, de domesticação agrícola e modernização concentradora, da pecuária de corte e da produção de grãos e do desmatamento, como refere Mazzeto Silva (2009). Ressalta que das unidades de conservação do Cerrado, $76 \%$ foram criadas nos últimos dez anos, $70 \%$ dessas unidades de proteção integral não admitem populações tradicionais no seu interior e que as Áreas de Proteção Ambiental (APAS) não se caracterizam pela presença de populações tradicionais. 0 Cerrado, portanto, tem significados distintos quanto ao uso e à apropriação de seus recursos: como lugar de negócio e como lugar de viver. Nesse sentido, o "desenvolvimento" no Cerrado tem como

Fevereiro de 2007, que propôs a redução das desigualdades de nível de vida entre as regiões; estratégias para estimular e apoiar processos e oportunidades de desenvolvimento regional, em múltiplas escalas; articular ações que, no seu conjunto, promovam uma melhor distribuição da ação pública e investimentos no território nacional (objetivos de inclusão social, produtividade, sustentabilidade ambiental e competitividade econômica).

${ }^{7}$ A PNOT expressou os esforços políticos e jurídicos do governo Lula em formular e implantar uma política de planejamento, pautada em diagnósticos e na formulação de diretrizes e instrumentos, para o país. Entretanto, demandam-se estudos que possam avaliar em que medida o Programa de Aceleração Crescimento (PAC), lançado em 2007, influenciou o arrefecimento da PNOT. Esse marca o início do segundo mandato do governo, e é também o mesmo ano em que foi decretado o grupo interministerial para formular a PNOT, ou seja, as condições de possibilidade de avançar nas reformas e na transformação da sociedade, do Estado e do território brasileiros estavam postas, mas não se efetivaram. O élan inicial que alimentavam grandes esperanças de futuro promissor para o Brasil, com o governo Lula, arrefeceu.

${ }^{8}$ As abordagens e concepções dos geógrafos portugueses, João Ferrão $(2010,2011)$ e Jorge Gaspar (1995). 
consequências: a "erosão genética da perda da biodiversidade" e a "erosão cultural dos modos de vida e apropriação da natureza”.

Parece haver certo consenso, na literatura corrente, que a década de 1980 ficou marcada pelo esgotamento do modelo de desenvolvimento nacional, com o "esgotamento do modelo de substituição de importações", a crise fiscal e os desequilíbrios macroeconômicos. Na década de 1990, um "novo" modelo é instituído como princípio norteador, ancorado na integração da economia nacional ao mercado internacional. Privatizações e reformas liberalizantes fizeram parte desse modelo e passaram a comandar a integração das regiões ao mercado internacional. Por meio de eixos nacionais de integração e desenvolvimento, a região Centro-Oeste se conectou ao mercado internacional, como refere Pereira (2019). A implantação desse modelo de desenvolvimento foi impulsionada no governo de Fernando Henrique Cardoso (1995-2002).

A territorialização do capital disputa com as populações tradicionais o domínio da natureza, a exploração dos recursos naturais, impõe padrões de uso e consumo, submete as relações sociais à lógica mercantil. De outro modo, as populações tradicionais buscam preservar seus saberes e fazeres, suas tradições e costumes, como também criam formas de organização política e de resistência. Da qual é exemplo a Rede Cerrado, constituída de cem entidades e movimentos sociais, que reivindicam a criação de Unidades de Conservação de Uso Sustentável.

Paradoxalmente, observa Chaveiro $(2005,2019)$, a valorização e o crescente comprometimento da sociobiodiversidade do Cerrado coexistem na disputa simbólica das representações e dos sujeitos, das formas de uso e das atividades econômicas. A proposição é a de que a elucidação de quaisquer que sejam os componentes do Cerrado, inclusive a sociobiodiversidade, deve-se partir de uma "abordagem territorial", que seja relacional e multidimensional. Essa proposição tem consequências teóricas, conceituais e políticas porque implicam em ultrapassar alguns esquemas correntes de pensamento, sobretudo as abordagens ambientalistas do Cerrado fundadas na separação entre o conceito de bioma e território. É possível afirmar que tal separação ignora a territorialidade humana, componente fundamental da concepção de Cerrado como território e desconsidera a biodiversidade natural em relação com a diversidade social e cultural implícitas no conceito de sociobiodiversidade.

\section{CONSIDERAÇÕES FINAIS}

A definição dos propósitos do ordenamento e do desenvolvimento territorial não é isenta de ideologia e se apresenta por meio do discurso que o Estado dissemina, revelando-se de modo mais ou menos explícito nas leis e políticas públicas. Não se pode ignorar que as políticas demandam instrumentos de ordenamento territorial e um aparato jurídico-político para serem legalmente implementadas. É difícil discordar de alguns desses propósitos quando consideramos os valores humanos que comportam: o desenvolvimento socioeconômico equilibrado, a melhoria da qualidade de vida, a gestão responsável dos recursos naturais, a utilização racional do território, etc. Muitas vezes o componente ideológico se revela mais nos meio empregados para a consecução desses propósitos, do que na sua finalidade.

Os desafios que se apresentam às políticas de ordenamento e desenvolvimento territorial consistem de um enfrentamento da: tradição de políticas setoriais que não alcançam o território nacional de forma integrada; hegemonia de um padrão de desenvolvimento que exclui várias formas de uso do território pelos diversos sujeitos que o ocupam, como as populações indígenas, quilombolas, ribeirinhas, sertanejas, etc.; da herança da formação territorial brasileira, cuja ocupação do território, desde a colonização, se fez pela violência e exclusão social da população nativa e/ou escravizada pelo empreendimento colonial.

Conceber o Cerrado como território implica em considerar, mas, também ultrapassar sua dimensão apenas como bioma, e avançar na compreensão de sua formação histórica, social e cultural constituída pelos usos, hábitos e costumes das comunidades tradicionais e dos "povos cerradeiros", cuja identidade territorial abarca a cultura material e simbólica. O substrato natural, os povos e sua história, com suas técnicas e seus usos, coexistem e configuram a territorialidade do Cerrado, que se expressa na forma da sociobiodiversidade. Esta, por sua vez, desafia as políticas nacionais de ordenamento territorial porque não permite a separação entre bioma, povos e território. A própria noção de sociobiodiversidade demanda a inseparabilidade entre a preservação da biodiversidade e da diversidade sociocultural. 
A sociobiodiversidade pode e deve se constituir num princípio de ordenamento territorial a balizar as políticas públicas. As Reservas Extrativistas também podem se constituir como modelo de Unidade de Conservação e como condição de possibilidade de reconstituir grupos sociais, comunidades sertanejas, e tantas outras formas de comunidades tradicionais que resistem e buscam garantir a sociobiodiversidade do território do Cerrado. É importante que existam modelos de ordenamento territorial que, em alguma medida, se articulem como política pública no território nacional e, simultaneamente, preserve a diversidade regional, como um dos patrimônios brasileiros (BACELAR, 2008). Todavia, para que esses modelos logrem êxito, os desafios apontados devem ser ultrapassados num movimento, simultaneamente, teórico e científico e pela ação do Estado, por meio de políticas públicas. Como território, o Cerrado também é palco de conflitos e objeto de disputas materiais, simbólicas e ideológicas. Nesse sentido, uma política nacional de ordenamento territorial deve considerar a coexistência da sociobiodiversidade e os conflitos pela posse e domínio do Cerrado.

\section{AGRADECIMENTOS}

Agradeço à Coordenação de Pessoal de Nível Superior (CAPES), Brasil, pelo auxílio financeiro, sob a forma de bolsa de estudos, para a realização do estágio pós-doutoral, no âmbito do projeto: Desenvolvimento territorial e sociobiodiversidade: perspectivas para o mundo do cerrado, aprovado no Edital PGPSE n. 42/2014.

\section{REFERÊNCIAS}

ALMEIDA, F. G. de; SOARES, L. A. A. (Orgs.). Ordenamento territorial: coletânea de textos com diferentes abordagens no contexto brasileiro. Rio de Janeiro: Bertrand Brasil, 2009.

ALVES, L. da S. F. Planejamento e ordenamento territorial do turismo na Região Metropolitana de Natal - RN. Universidade Federal do Rio Grande do Norte. Dissertação de Mestrado, 2009, Natal RN. Disponível em: <http://repositorio.ufrn.br/rmnatal/dissertaçoes/pdf> (12/12/2011). Acesso em: 22 de janeiro de 2020 .

. Cultura de ordenamento territorial: conceituações e perspectivas histórico-analíticas. Mercator. V.13, n.3, p. 63-73, set./dez. 2014. https://doi.org/10.4215/RM2014.1303.0005

ALVES, C. de S. A tentativa de uma política nacional de ordenamento territorial no Brasil: a PNOT (2003-2009). Registro, críticas e reflexões. 2017. 306 f. Tese (Doutorado em Planejamento Urbano e Regional). Faculdade de Arquitetura e Urbanismo, Universidade de São Paulo, São Paulo, 2017. Disponível em: teses. usp.br/teses/disponíveis/16/16139/tde-12122017-152346/publico. Acesso em: 10 de fevereiro de 2020.

ARROYO, M. M. Território nacional e mercado externo: uma leitura do Brasil na virada do século XX. 2001. 250 f. Tese (Doutorado em Geografia) Universidade de São Paulo, São Paulo, 2001.

BACELAR, T. de A. Entrevista - A diversidade regional é um dos patrimônios brasileiros que farão diferença no século XXI. In:__ São Paulo, Brasil: IPEA, 2008. Revista Desafios do

Desenvolvimento. Ano 5, n. 45, p. 22-24. Disponível em:

<http://www.ipea.gov.br/desadios/index.php>. Acesso em: 10 de fevereiro de 2020.

BADIE, B. O fim dos territórios. Lisboa: Instituto Piaget, 1997.

BECKER, B. K. Por um redescobrimento do Brasil. In: CASTRO, I. E. de; MIRANDA, M.; EGLER, C. A. G. (Orgs.). Redescobrindo o Brasil: 500 anos depois. Rio de Janeiro; Bertrand Brasil: FAPERJ, 1999. p. 11-23.

BRASIL. MI-IICA. PNOT - Para pensar uma Política Nacional de Desenvolvimento Territorial: Anais da Oficina sobre a Política Nacional Ordenamento Territorial, Brasília, 13-14 de novembro de 2003. Brasília-DF: Disponível em: <http://www.mi.gov.br/c/document_library/get>. Acesso em: 20 de 
agosto de 2018.

BRASIL. MI-IICA. Apresentação dos Documentos Temáticos - Tema 2. Brasília-DF: MI- SDR, CDS, UnB, IICA ABIPTI, 2006. Disponível em:

<http://www.mi.gov.br/documents/24915/44788/PNOT_Temas+02>. Acesso em: 20 de agosto de 2018.

BRASIL. MI-SDR. Documento Temático 1. Padrão de uso e ocupação do território e suas principais tendências de transformação. Brasília-DF: MI- SDR, CDS, UnB, IICA ABIPTI, 2006. Disponível em: <http://www.mi.gov.br/documents/24915/44788/PNOT_Temas+01>. Acesso em: 15 de setembro de 2018.

BRASIL. MI- SDR. Documento Temático 2. Avaliação dos impactos de Planos, Programas e Projetos no Uso e Ocupação do Território no Brasil. Brasília-DF: MI- SDR, CDS, UnB, IICA ABIPTI, 2006. Disponível em: <http://www.mi.gov.br/documents/24915/44788/PNOT_Temas+02>. Acesso em: 15 de setembro de 2018.

BRASIL. MI- SDR. Documento Temático 3. Políticas de Ordenação do Território - A contribuição de experiências nacionais e internacionais. Brasília-DF: MI- SDR, CDS, UnB, IICA ABIPTI, 2006. <http://www.mi.gov.br/documents/24915/44788/PNOT_Temas+03>. Acesso em: 15 de setembro de 2018.

BRASIL. MI- SDR. Documento Temático 4. Logística e Ordenamento do Território. Brasília-DF: MISDR, CDS, UnB, IICA ABIPTI, 2006.

<http://www.mi.gov.br/documents/24915/44788/PNOT_Temas+04>. Acesso em: 15 de setembro de 2018.

BRASIL. MI- SDR. Documento Temático 5. Espaços geográficos sob poder da União - Uma avaliação da experiência na perspectiva de uma PNOT. Brasília-DF: MI- SDR, CDS, UnB, IICA ABIPTI, 2006. <http://www.mi.gov.br/documents/24915/44788/PNOT_Temas+05>. Acesso em: 15 de setembro de 2018.

BRASIL. MI- SDR. Documento Temático 6. Avaliação do Aparato Institucional e Jurídico-legal na perspectiva da PNOT, Brasília-DF: MI- SDR, CDS, UnB, IICA ABIPTI, 2006.

<http://www.mi.gov.br/documents/24915/44788/PNOT_Temas+>. Acesso em: 15 de setembro de 2018.

CARLOS, A. F. A. Os caminhos da geografia humana no Brasil. Boletim Paulista de Geografia, São Paulo, n. 71. p. 129-142, 1992.

CHAVEIRO, E. F. Símbolos das paisagens do Cerrado Goiano. In: ALMEIDA, M. G. de (Org.). Tantos Cerrados. Goiânia: Vieira, 2005. p. 47-62.

Por uma abordagem geográfica do Cerrado: a negação de um bioma diverso, a afirmação de um território desigual - Cartas de luta. 2019. 326 f. Tese (Concurso Professor Titular). Universidade Federal de Goiás, Goiânia, 2019.

CLAVAL, P. O território na transição da pós-modernidade. GEOgraphia, ano 1, n.2, p. 7-26, 1999. https://doi.org/10.22409/GEOgraphia1999.12.a13349

FERRÃO, J. Governança e ordenamento do território, reflexões para uma governança territorial eficiente, justa e democrática. Prospectiva e Planeamento. Vol. 17, 2010, p. 129-139.

O ordenamento do território como política pública. Lisboa: Fundação Calouste Gulbenkian, 2011.

GASPAR, J. Conceito de ordenamento do território. Instituto Geográfico Português - IGP, LisboaPortugal, mar. 1995. Disponível em: 
<http://www.ftp.igeo.pt/instituto/cegig/got/17_Palnniny/Files/indicadores/conceito_ot.pdf>. Acesso em: 15 de agosto de 2018.

GREGORY, D. Teoria social e geografia humana. In: GREGORY, D.; MARTIN, R.; SMITH, G. (Orgs.). Geografia humana - sociedade, espaço e ciência social. Rio de Janeiro: Jorge Zahar, 1996. p. 90122.

HAESBAERTH, R. Des-territorialização e identidade: a rede "gaúcha" no nordeste. Niterói: EDUFF, 1997.

Território e globalização. GeoUERJ: Revista do Departamento de Geografia, UERJ. Rio de Janeiro, n.5, p. 7-19, jan./jun. 1999.

INOCÊNCIO, M. E. O PRODECER e as tramas do poder na territorialização do capital no cerrado. 2010. 271 f. Tese (Doutorado em Geografia). Universidade Federal de Goiás, 2010. Disponível em: <http://www.posgeo.iesa.ufg.br/ppgeo/índex.php/publicações/banco-de-teses-doppgeo/download/11-2010/168.maria-erlan-inocencio>. Acesso em: 10 de março de 2020.

MORAES, A. C. R. Bases da formação territorial do Brasil: o território colonial brasileiro no "longo" século XVI. São Paulo: Hucitec, 2000. https://doi.org/10.7147/GEO2.1145

Território e história no Brasil. São Paulo: Hucitec, 2002.

PEREIRA, M. H. Cerrado e políticas públicas: relações complexas e antagonismos num bioma ameaçado. In. IV Jornada Internacional de Políticas Públicas. Neoliberalismo e lutas sociais: perspectivas para as políticas públicas. Universidade Federal de Pernambuco, 2009, p.1-10. Disponível em: <http://www.joinpp.ufma.br/jornadas/joinppIV/INDICE\%EIXO\%LUTAS\%SOCIAIS>. Acesso em: 10 de março de 2020.

PIRES, M. J. de S. Texto para discussão. Instituto de Pesquisa Econômica. Aplicada.- Brasília : Rio de Janeiro: IPEA, 2019. Disponível em: <http://www.ipea.gov.br>. Acesso em: 10 de março de 2020.

RÜCKERT, A. A.; ALBUQUERQUE, E.S. de. Uma contribuição ao debate sobre a política de ordenamento territorial - PNOT. Mercator, Revista de Geografia da UFC, ano 4, n.8, p.15-26, 2005.

SANDER, S.D.; MAIORKI, G.J. Ordenamento do território: um tema pouco discutido no Brasil. Resenha do livro de João Ferrão: Ordenamento do território como política pública. 2011. In: Ano 2 , UFC, DRd - Desenvolvimento Regional em debate, 2012. N.1. Revista Eletrônica do Programa de Mestrado em Planejamento Urbano Regional da Universidade do Contestado, p. 232-237. Disponível em: <http://WWW. Periódicos.unc.br/índex.php/drd/article/view/217/2827>.

https://doi.org/10.24302/drd.v2i1.217

SANTOS, M. Metamorfoses do espaço habitado. São Paulo: Hucitec, 1988.

O retorno do território. In: SANTOS, M; SOUZA, A. A. de; SILVEIRA, M. L. (Orgs.). Território globalização e fragmentação. São Paulo: Hucitec, 1994. p. 15-20.

. A natureza do espaço: técnica e tempo, razão e emoção. São Paulo: Hucitec, 1996.

SANTOS, M.; SIVEIRA, M. L. O Brasil: território e sociedade no início do século XXI. Rio de Janeiro: Record, 2001.

SANTOS, M. A revanche do território (3/8/1997). O país distorcido: o Brasil, a globalização e a cidadania. São Paulo: Publifolha, 2002a. p. 84-86.

. Revelações do território globalizado (16/7/2000). O país distorcido: o Brasil, a globalização e a cidadania. São Paulo: Publifolha, 2002b. p. 98-101. 
SILVA, A. C. da. $\mathbf{O}$ pensamento geográfico brasileiro na travessia do século $\mathbf{X X}$ para 0 XXI: 0 território na trama das significações imaginárias. 2010. 531f. Tese (Doutorado em Geografia). Universidade Estadual Paulista, 2010.

.Território e signigicações imaginárias no pensamento geográfico brasileiro. Goiânia: Cegraf, 2013.

. O território no pensamento geográfico brasileiro contemporâneo. Boletim Goiano de Geografia, v. 36, n. 1, p. 27-47, jan./abr, 2016. https://doi.org/10.5216/bgg.v36i1.40364

SILVA, S., BORGES, L. As políticas de ordenamento territorial e de planejamento regional no Brasil nos anos 1990 e 2000: um breve estudo sobre os ENIDS, o PNDR, o PAC e os Territórios da Cidadania. Anais do I Congresso Brasileiro de Geografia Política e Geopolítica e Gestão do Território, 2014. Disponível em: <http://www.editoraletra1.com/anais-congeo/arquivos/978-85-63800-17-6-13541367.pdf>. Acesso em: 24 de outubro de 2019.

MAZZETO SILVA, C. E. Ordenamento territorial no cerrado brasileiro: da fronteira monocultora a modelos baseados na sociobiodiversidade. Desenvolvimento e Meio Ambiente, n. 19, p. 89-109, jan./jun. 2009. Editora UFPR: Curitiba. Disponível em:

<http://www.conflitoambiental.icict.fiocruz.br/sist_arq/arquivos/(2009)_mazzetto_silva__ordenamento_territorial_no_brasileiro.pdf.> . Acesso em: 24 de outubro de 2019. https://doi.org/10.5380/dma.v19i0.16407

THÉRY, H. et alii. O padrão de uso e ocupação do território e as principais tendências de transformação. Projeto Elaboração de Subsídios Técnicos e Documento Base para a Definição da Política Nacional de Ordenamento do Território. Brasília: Universidade de Brasília/Centro de Desenvolvimento Sustentável, 2006.

Recebido em: 20/09/2020

Aceito para publicação em: 17/11/2020 